\title{
EMBATES HISTORIOGRÁFICOS NA ANTIGUIDADE TARDIA: RELEVÂNCIAS SOBRE OS CONCEITOS DE IDENTIDADE, ETNOGÊNESE E TRADITIONSKERN.
}

Marlon Citon ${ }^{1}$

RESUMO: Este trabalho tem como proposta analisar os embates historiográficos constituídos na formação de três conceitos: Identidade, Etnogênese e Tradionskern, sobre o período temporal da Antiguidade Tardia, em especial aos embates entre a Universidade de Viena e Toronto. Como parte de um artigo de análise historiográfica, buscamos, de forma sucinta e objetiva, apresentar e problematizar diversas concepções constituídas por autores e linhas interpretativas, apontando determinados embates epistemológicos na formação de terminadas perspectivas. Concerne-se, assim, numa interpretação do historiador frente ao cenário historiográfico de tais trabalhos acadêmicos, nas referentes inclusões e exclusões de obras e autores. Dentro do viés da legitimação historiográfica, tais conceitos referem-se a importantes instrumentais para pensar o contexto do período e fundamentar ideias, tornando-os importantes em uma análise ampla.

Palavras-chave: Antiguidade Tardia, Historiografia, Identidade, Etnogênese, Tradionskern.

\section{Introdução}

O conhecimento histórico, decorrente da análise interpretativa do pesquisador, é resultante da conjuntura temporal, social e pessoal em que este está inserido. Neste pré-âmbito, podemos delimitar conceitos que seriam importantes para fomentar uma pesquisa histórica em determinados campos historiográficos. Na Antiguidade Tardia, perspectivas sobre os conceitos de Identidade e Etnogênese, decorrendo na noção de Traditi-

\footnotetext{
${ }^{1}$ Graduando em História, Universidade Federal do Paraná. Membro discente do Núcleo de Estudos Mediterrânicos.
} 
onskern, mostram-se relevantes na investigação histórica: como ocorriam as relações entre populações de diferentes origens e suas representações nas fontes, juntamente com a historiografia constituída sobre. Tais nominativos indicam a necessidade de qualificações e concepções de conceitos que refletiriam o respectivo período de forma concernente, evitando o anacronismo.

Para introduzir este trabalho utilizamos de aporias clássicas referentes ao ofício do historiador, muito presentes e importantes ao assunto que desenvolveremos nas próximas páginas, buscando apontar o objeto de forma sucinta dentro de uma metodologia específica, em especial, na constituição de conceitos.

De forma sintética e rápida, pretendemos introduzir tais noções para o melhor entendimento de conceitos, constituídos pela historiografia, não sujeitando de forma total as interpretações apresentadas pelos autores, intento impossível de ser cumprido em apenas um artigo $^{2}$. Frente ao tipo de análise proposta e interpretativa dos autores, esse trabalho possui concepções próprias, pela inclusão e exclusão de obras, autores e linhas historiográficas, já que decorre em escolhas em sua fundamentação. Assim, abrimos espaço para possíveis diferentes noções e constante revisão de concepções aqui expostas, não colocando opiniões pessoais sobre cada

${ }^{2}$ Frente a abstinência de outros conceitos importantes para a constituição da discussão historiográfica, apontamos a impossibilidade de trabalhar com uma conjuntura metodológica maior, que não abrangeria de forma condizente em um trabalho que possui uma estruturação sintética e específica. Assim, apresentaremos, ao longo do trabalho, uma bibliografia que poderá ser consultada para maiores informações de conceitos, contexto e obras na perspectiva histórica sugerida acima. 
linha historiográfica, fato que diminuiria a amplitude de exame do historiador. Tal conteúdo possui nível de dificuldade elevado para fazer sua análise, já que as interpretações diferenciam-se através de conceitos bem localizados e por discussões historiográficas intensas.

\section{Duas escolas, muitos historiadores.}

Ao longo do decorrer do século XX, a constituição historiográfica acerca das relações entre o "Mundo Bárbaro" e o "Mundo Romano" foi relevante para pensarmos os conceitos de Identidade, Etnogênese e Gens. ${ }^{3}$ São termos os quais promovem diferenciações metodológicas entre autores, decorrentes de variadas conjunturas de suas formações acadêmicas e intelectuais. O desenvolvimento conceitual referente à área tornou-se importante pela conjuntura apresentadas pelas fontes, contexto de mudanças

${ }^{3}$ As concepções de Identidade são basilares dentro de uma compreensão do embate historiográfico aqui apresentado, o qual possui a impossibilidade de conceitualização de forma sintética devido a complexidade de tal. De modo mais geral, o conceito é discutido devido a fundamentação de cada perspectiva, ponto que é ressaltado no decorrer desse trabalho. Etnogênese concerne a ação recorrente de relações entre diferentes populações étnicas durante as movimentações nos séculos IV, V e VI. Já no caso da Gens, tem a conotação de uma família ou população. Refere-se a um fenômeno muito importante na constituição de político/social da Antiguidade Tardia, os vínculos que pessoas possuíam no desenvolvimento de um clã ou grupo nobiliárquico. Possui outra interpretação por ser utilizado desde a época da República Romana e Principado para considerar determinadas famílias influentes de Roma. Assim, apontamos para a mudança de denotação do conceito frente às mudanças temporais as fontes, o que é apresentado pela historiografia, e referente uso por Historiadores Tardo-Antigos e Medievalistas. Wolfram aponta que Gens refere a uma comunidade com origem biológica comum, sendo Gentes uma perspectiva da mistura de diversas etnias, em caráter polissêmico. (Cf. WOLFRAM. P.5) 
entre um mundo político/institucional Romano para um Romano/Bárbaro. Pensar interações contextuais já elenca a concepção clássica de Arnaldo Momigliano, de relações diretas entre povos ${ }^{4}$. No caso da Antiguidade Tardia, entendemos que concerne a um período de transição e transformação, em que conceitos e vocábulos utilizados pelas fontes podem ter significados diferentes, referentes a uma nova perspectiva do período ${ }^{5}$. Assim, examinar as fontes torna-se algo complexo, decorrente de diversas análises e formação de interpretações. Tentando localizar a discussão, mesmo de forma sintética, podemos apontar duas linhas basilares para o desenvolvimento de trabalhos. Por um lado, historiadores da "Escola" de Viena, tendo vínculos estreitos com uma herança alemã na teoria da história e historiografia. Por outro lado, a "Escola” de Toronto aponta para interpretações questionadoras de determinadas perspectivas elencadas pela historiografia clássica e de língua alemã, relevantes com concepções de críticas elencadas pela antropologia “instrumentalista” dos anos 1950. Além de tais simplificações frente complexidade do assunto, pesquisado-

\footnotetext{
${ }^{4}$ Momigliano possui obra vasta sobre a Grécia Antiga, Cristianismo e Império Romano. Suas referências apontam para trabalhos sobre historiografia e análise de especificidades do período temporal. Sobre a concepção de interação, sua obra Alien Wisdom: The Limits of Hellenization aponta como referencial, demonstrando relações entre populações que estariam presentes na Grécia de Alexandre Magno. Interessante registro, pois Nietzsche denotou, em seu trabalho A Filosofia na Época trágica dos Gregos, as relações que filósofos teriam de outras regiões e perspectivas na formatação da Escola Jônica e Eleata. O que pode trazer concepções similares em alguns pontos.

${ }^{5}$ Para considerações gerais sobre a Antiguidade Tardia, dentro das noções de transfomação e transição, apontamos o referênte trabalho: FRIGHETTO, R. Antiguidade Tardia: Roma e as Monarquias Romano - Bárbaras numa época de Transformações (Séculos II-VIII). Curitiba: Juruá, 2012.
} 
res fora de vínculos estão presentes ao longo do mundo, principalmente na Europa e Estados Unidos, caso de Gillett, Kulikowski, Woods, Heather, entre outros ${ }^{6}$.

\section{"Escola" de Viena}

O historiador mais importante na constituição de uma interpretação problemática inicial concerne a Reinhard Wenskus. Em Stammesbildung und Verfassung: Das Werden der frühmittelalterlichen gentes, trabalho clássico para a conceitualização da Etnogênese (Stammesbildung), Etnografia e Traditionskern, Wenskus apresenta a "etnogenidade" como transmissora de tradições étnicas na formação de uma identidade em uma população ${ }^{7}$, interpretação que a formação étnica e política pautam-se em elites nobres como formadoras de uma identidade, uma única Gens frente às diversas Gentes. Notamos, desse modo, a construção de ideias estáticas, modeladas na diferenciação territorial, em elites nobiliárquicas, denotando uma diferenciação biológica de populações ${ }^{8}$. Suas concepções indicam a

\footnotetext{
${ }^{6}$ Existe ampla historiografia sobre o tema, muitos autores e muitas interpretações. Entendendo as limitações desse trabalho, indicamos que não referenciamos de modo total nesse artigo, mas quais estão mais presentes dentro do ambiente dos embates historiográficos da Universidade de Viena.

${ }^{7}$ Nesse caso, Identidade tem uma conotação mais ampla, além de simples manifestação de traços culturais, mas representação política/social, referenciando uma população.

${ }^{8}$ A obra de Wenskus é problemática para fazer análises, já que não existem traduções dos originais em língua alemã, muito menos acesso longe de núcleos especializados. Assim, as proposições apresentadas aqui remetem, principalmente, aos trabalhos de Walter Pohl: Ethnicity, Theory, and Tradition: A Response e Strategies of Distinction.The construction of Ethnic Communities, 300-800; juntamente com outras perspectivas apresentadas por Gillett e Bowlus.
} 
formação de um paradigma dentro da historiografia, por ser uma teoria conceitual amplamente desenvolvida em língua alemã, além de extremamente discutida. Ele foi um dos pesquisadores que formaram a ideia geral de Etnogênese, indicando propostas de como certas populações surgiram, muitas vezes apontando características Germânicas provenientes da Idade do Ferro em tal função (C.f. BOWLUS, P. 243) ${ }^{9}$. A concepção de Wenskus resulta na noção de Traditionskern ${ }^{10}$, a nobreza como um núcleo de tradição, formadora de uma identidade étnica frente a hordas de guerreiros de diversas origens, não esboçando uma heterogeneidade identitária presente nesses povos ou a tentativa de identificação dos mesmos através de características étnicas, mas pela especificidade de uma Gens. Importante apontarmos a noção militar como ponto chave para a concepção de Etnogênese e Identidade de Wenskus, já que resulta na ideia de Traditionskern na perspectiva de legitimação de tais guerreiros não apenas por um passado mítico, mas pela vitória em batalha ${ }^{11}$. Referente ao contexto de forma-

${ }^{9}$ Etnogenesis: The Tyranny of a Concept. Artigo inserido na edição organizada por Gillett presente na bibliografia.

10 Gillett define a origem da concepção: "This theory of the origins of ethnic groups (ethnogenesis) centres on the concept of a binding core of tradition (Traditionskern) either embodied in an aristocratic elite which 'bears' the group's identity-giving traditions, or transmitted by less tangible 'ethnic discourses'. The theory is essentially philological (in the original sense of the word) in approach but framed with reference to contemporary thought in the social sciences. Traditionskern theory posits the replication of group identity through the subscription by members to a mythic narrative of the group's past (the 'core of tradition'), focused on the divine descent of its rulers.” (GILLETT, 2002)

11 "Vitória militar" releva ao próprio conceito romano de Vitória, além de representação religiosa. No caso dos povos bárbaros, sua origem militar e desenvolvi- 
ção de sua obra remonta-nos ao Nacionalismo de emeados do século XX, relevando noções enquadradas com o recorte temporal, social e político em que o pesquisador estava inserido ${ }^{12}$. Em si, Wenskus ajudou a popularizar o termo Gens e Tradionskern, resultando em diferentes interpretações de sua obra por parte de historiadores atuais ${ }^{13}$.

Outra obra importante é Die Goten ${ }^{14}$ de Herwig Wolfram, a qual representa uma noção de Etnogênese parecida com a de Wenskus e mais aceita no cenário historiográfico, delimitando linhagens nobiliárquicas e, consequentemente, uma formação identitária como formadora de identidade. Traditionskern é um conceito muito importante para Wolfram, já que a noção de identidade relaciona-se com as linhagens nobres e autoridade sobre uma população específica, o que ele desenvolveu muito bem em sua análise sobre os Godos. Porém, atualmente, é muito criticada por

mento político, a Vitória representava o objetivo de tais populações em sua formação lógica social e política.

12 Como apontado por Gillett, o desenvolvimento de teorias etnográficas, resultante nos conceitos de Etnogênese e Tradionskern é decorrente do avanço do Nacionalismo. Em oposição, houve a criação de uma antropologia "instrumentalista” nos Estados Unidos pelos anos 1950 que possuía como objetivo identificar a "etnicidade" de forma social e culturalmente construída. Wenskus é identificado, muitas vezes, como um "racialista”, o que releva para uma interpretação contrária por historiadores com vínculos relacionados a tal perspectiva. Tais noções denotam a interpretação pessoal de Gillett.

13 Esse ponto é bastante problemático, pois dependente a interpretação de sua obra há discordâncias na legitimação de pontos específicos frente a Etnogenese/Etnologia e o Gens. Murray considera Wenskus como uma interpretação ideológica para a “Teoria da Etnogenese”, mas não biologicista apenas.

${ }^{14}$ Obra lançada inicialmente em 1979 em Alemão sobre o título Die Goten und ihre Geschichte, é disponível com uma tradução em inglês desde 1988, denominado History of the Goths. 
determinados núcleos acadêmicos, sendo acusada de "densamente elitista e enraizada em tradição autoritária” ${ }^{15}$.

Contudo, é notório o desenvolvimento de modelos interpretativos sobre perspectivas de autores ao longo dos embates historiográficos, diminuindo a problemática dos conteúdos apresentadas em obras extensas ${ }^{16}$. No caso de Wenskus e Wolfram não é diferente, a aplicabilidade de suas interpretações restringe-se ao tipo de metodologia e concepções dos historiadores atuais nesse campo, o que possui generalizações significativas sobre seus trabalhos. Wenskus é apontado como biologicista ou ideológico, dependente a interpretação, porém o acesso a sua obra é bastante restrito, colocando em questão a veracidade interpretativa ${ }^{17}$. Wolfram é muito mais lembrado pela aplicabilidade contextual de sua obra, na perspectiva de Traditionskern, do que um pesquisador problemático na formação historiográfica, o que é bastante reducionista. Ele faz exercício da crítica,

15 Alexander Murray aponta como uma concepção enraizada na historiografia alemã, desde tempos anteriores a Wenskus com a "lordship theory", o que resultaria na homogeneização das Gentes e formação da Teoria da Tradionskern. (Cf. MURRAY; 2002)

16 "Quem controla o passado, controla o futuro; quem controla o presente, controla o passado." (Nineteen Eighty - Four. ORWELL). Essa frase é aplicada não apenas no âmbito político/social/econômico, mas no cenário historiográfico, nas escolhas e legitimidades de discussões e omissões de interpretações.

${ }^{17}$ Murray possui um capítulo de livro bastante interessante sobre Wenskus, nele aponta o uso e do termo genérico Stamm, concernente ao Gens. Em sua interpretação sobre o autor austríaco, denota o uso da concepção de Traditionskern na formação de conhecimento etnográfico. Considera como concepções idealistas e não biologicistas, pois Wenskus teria fundamentado sua concepção frente os ideais nacionalistas, como já apontado na "lordship theory" na nota 14. Para maiores informações verificar em o capitulo: Reinhard Wenskus on 'Ethnogesis', Ethnicity, and the Origin of the Franks, presente no livro editorado por Gillett. 
além de um levantamento bibliográfico na introdução de seu livro Die Goten, apontando que a aplicabilidade de estudos filológicos e historiográficos sobre os povos bárbaros estão relacionados, respectivamente, com o Romantismo Francês e os Historicismo Alemão ${ }^{18}$. O autor denota que essas perspectivas interpretativas utilizavam-se do conceito de Gens na legitimação de ideias biologicistas, a busca por uma vitalidade Germânica em um remoto passado tribal dos povos bárbaros, os quais formaram as identidades nacionais modernas. O exercício da crítica por Wolfram não é apenas rejeitar interpretações, mas utilizar de concepções válidas para sua análise metodológica ${ }^{19}$.

A perspectiva de Wolfram acima é apresentada após a crítica às concepções biologiscistas, denotando que a problemática do conceito de Gens, na “etnogenidade” presente em determinadas populações bárbaras. Porém, a unidade e constituição de características comuns entre indivíduos de diferentes ascendências implica ao exército, ao combate sobre a autoridade de líder, uma nobreza nobiliárquica específica, no comando

${ }^{18}$ Wolfram aponta o trabalho filológico de Johann Christoph Gottsched e a importância de Michael Schmidt na constituição da migratio gentium em consonância com o Volkerwanderung. O uso do conceito de Gens por Schmidt é importante na constituição do conceito, na relação com significados distintos.

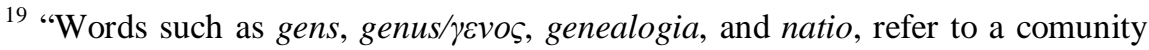
of biological descent. The tribal sagas, however, equate people with army and thus remain true historical reality. In addition, the sources attest the polyethnic character of gentes. These gentes never comprise all potencial members of a gens but instead always mixed. Therefore their formation is not a matter of common descent but one of political decision. Initially this implies not much more than the ability to unite and keep together the multitribal groups that make up any barbarian army.” (WOLFRAM, 1990) 
Cadernos de Clio, Curitiba, n. ${ }^{\circ}$ 4, 2013

bélico. Assim, o conceito de Traditionskern torna-se referencial em sua obra.

No decorrer do desenvolvimento de novas ideias no âmbito da Antiguidade Tardia e Início da Idade Média ${ }^{20}$, diferentes proposições sobre os conceitos de Etnogênese, Gens e Traditionskern foram concebidos. A Universidade de Viena é palco de formação de novas concepções concernentes ao tema, problematizações metodológicas sobre o que seriam fontes de estudos e seus usos são frequentes. Pensar atualmente as noções introduzidas inicialmente por Wenskus e Wolfram necessita indicar Walter Pohl, como um "herdeiro” de Wolfram, já que foi orientado por este. Pohl denota a abstenção da "bipolarização" de confiabilidade das fontes, considerando extratos e tradição oral como legítimos, fato que seria considerado inapropriado por alguns historiadores. A análise de textos “literários” seria importante na opinião do autor, já que suas formações tiveram uma finalidade em um contexto específico, além de ampliar os horizontes na interpretação do que formaria uma identidade étnica. Pohl aponta que o conceito de Etnogênese é maleável, longe de uma estaticidade apontada pela “Escola” de Toronto. No caso do conceito de Traditionskern, Pohl utiliza-o, porém seu uso restringe-se a uma concepção específica, a problematização do mesmo na aplicabilidade em análise de fontes. A discussão sobre a utilização do conceito é recorrente no âmbito acadêmico, já que determinadas perspectivas sempre estão em discussão e não identifi-

${ }^{20} \mathrm{O}$ uso de determinada nomenclatura é relativa ao pesquisador e suas apropriações metodológicas. Assim, para não excluirmos aqueles que usam um determinado conceito, preferimos citar ambos, fato que não indica parcialidade por parte do autor. 
cariam de forma complacente os fenômenos decorrentes do contexto específico, mas de forma parcial ${ }^{21}$.

Pohl denota que a Etnogênese ocorria na transmissão de características étnicas de forma espontânea com o contato de uma população com outras. O núcleo étnico, formador de uma identidade pautada na nobreza, aponta-nos a fragilidade na raiz identitária, pois o tronco familiar, muitas vezes, não possuiria mais de três ou quatro gerações. Assim, a formação de uma tradição identitária representaria uma construção necessária à legitimidade de uma linhagem de poder. (C.f. POHL, 1997) Como apontado por Wolfram, a legitimidade de uma determinada família nobre pautava-se em cultos de Heróis e Deuses em uma remota origem, mesmo não havendo provas de tais afirmações ${ }^{22}$. Modificações nessas sociedades foram decorrentes desde as denominadas “migrações” (Völkerwanderung) da Escandinávia aos assentamentos posteriores, saindo de constituições tribais políticas/sociais bastante simples para poderes complexos pautados em certas famílias nobres. Em si, a apropriação de nominativos étnicos estavam muito mais relacionados a designações genéricas propostas pelos Romanos do que indicando de forma complacente a heterogeneidade das populações "bárbaras”, decorrente do processo de etnogênese. Devemos notar que a Etnografia é um conhecimento Romano e Grego, uma interpretatio romana, e como recorrente do trabalho do historiador, a parcialidade é notória em uma análise específica, na dificuldade de uso de fontes

21 Pohl continua a tradição historiografia de Wolfram, o qual já apontava para problemáticas de conceitos. Nesse caso, o historiador austríaco está em combate, dentro dos embates, caso que Wolfram não estava tão inserido.

${ }^{22}$ Wolfram apresenta de forma interessante sua perspectiva na introdução de seu livro Geschichte der Goten, utilizamos, aqui, de sua tradução. 
restritas e limitadas a interpretações romanas ${ }^{23}$. Desse modo, a origo gentes torna-se o modo, a busca, do tipo de concepção para fundamentar um tipo de população, sua história, através de uma construção romana de história.

A continuidade no uso do conceito de Traditionskern apresenta a problematização a uma possível perspectiva anacrônica do mesmo, remontando ao período Nazista no desenvolvimento do século XX, embates diretos ao uso de conceitos na análise histórica por causa dessa possível relação com teorias ideológicas ${ }^{24}$. Murray, por exemplo, compara a concepção de etnogênese e formação de poder político de Wenskus, Wolfram e Pohl de modo similar, apresentando de forma ideológica e não apenas biológica. A legitimação de um regime político através da história, de interpretações, não é algo novo nas discussões acadêmicas e no embate

${ }^{23}$ A problemática das fontes é bastante apontada nesse âmbito específico do conhecimento acadêmico. Kulikowski e Wolfram apontam esse problema no capítulo M. Nation versus Army: A Necessary Contrast? No livro organizado por Gillett.

${ }^{24}$ A diferenciação entre de Escolas Historiográficas tende a ser equivocada na maioria das vezes. Temos, por exemplo, diferenciações dicotômicas feitas para identificações de determinados pensamentos que não condizem com oposições em todas as áreas de desenvolvimento do saber científico. Assim, apresentando a dificuldade de análise das discussões nesse âmbito do conhecimento acadêmico, a diferenciação aqui apresentada possui noção de tal problemática, sendo aplicada apenas para melhor entendimento em um trabalho com perspectiva de análise sintética e não completa de conhecimentos historiográficos. Porém, com a análise mais aprofundada desse contexto de embate historiográfico percebemos que as querelas entre autores são muito mais complexas do que discordâncias de determinados conceitos. Fazemos essa ressalva, pois esse trabalho demonstra de forma extremamente sintética concepções muito mais complexas e que merecem um tratamento mais cuidadoso. Abrimos, assim, para possíveis trabalhos futuros nessas áreas. 
entre Pohl e Murray, o qual ocorre atualmente, torna-se bem nítida a problemática que os estudos sobre as populações bárbaras e os referentes processos que ocorriam no período histórico do século IV-VI.

Porém, o embate constitui de diversas formas: o uso metodológico de fontes e estudos antropológicos, por exemplo, estão no centro dessa problemática do cenário historiográfico. Pohl utiliza-se de Bourdieu e Fredik Barth em diversas de analises, o que coloca diferentes noções etnográficas apontadas por Wenskus. Murray aponta Pohl como um continuador de uma perspectiva desse historiador austríaco em conjunto com Wolfram, o qual não produziria nenhuma nova abordagem metodológica.

Pohl, na utilização de Traditionskern, aponta a mudança recorrente que o conceito apresentou juntamente com o desenvolvimento de uma historiografia. Mesmo sendo aplicado por autores, relacionados com o regime Nazista em Alemanha e Áustria, ou pelo menos aquisição desses regimes políticos de ideias apresentadas por eles, a aplicabilidade de um conceito muda frente ao exercício da crítica. Interessante notarmos como o autor refere ao trabalho de Otto Höfler na admissão de uma perspectiva ideológica do conceito de Traditionskern, tornando-o elistista e tendo origens no autoritarismo. A obra de Höfler é nitidamente relacionada com a concepção Nacional Socialista Alemã, dentro do projeto cultural Ahnenerbe $e^{25}$, na busca pelas origens dos mitos e autenticidade deles para a formação da nação alemã. Porém, Pohl aponta algumas características que

25 "To assume that the Germanic past had any bearing on these people means sharing the ideological assumption of the Germanic character of the early medieval kingdoms first proposed by scholars such as Otto Höfler in Nazi Germany. Moreover, a possibly royal Traditionskern as an agent of ethnincity is a deeply elitist concept rooted in an authoritarian ideology.” (POHL, 2002) 
Wenskus utilizaria pautado em tal historiador austríaco, porém, submentendo-o a crítica de ideias ${ }^{26}$. Em si, analise torna-se muito complexa, já que diversos fatores e conceitos são analisados quando dentro de perspectivas específicas ${ }^{27}$.

A decorrente distinção dos conceitos proposta por Pohl frente as críticas de historiadores da "Escola" de Toronto dispõem como ocorrem as discussões historiográficas sobre o respectivo tema atualmente. A aplicabilidade de conceitos, metodologias, origens de interpretações são características presentes no exercício de críticas dos autores apresentados acima.

\section{“Escola” de Toronto}

Para pensar a oposição às concepções clássicas formuladas pela “Escola” de Viena, temos que remeter à Universidade de Toronto. Possui como iniciador de estudos na área a obra primeira de Walter Goffart, The Narrators of Barbarian History. Como já denotado anteriormente, Toronto possui relevâncias como diferentes conceitos antropológicos, relevando a crítica a perspectivas “ideologias/biolicistas”, apontando para noções culturais/sociais, interações de poder, etc. No caso de Goffart, sua obra critica o conceito de Traditionskern por considerar Wolfram um continuador de uma historiografia anterior a Wenskus, em uma legitimação ideológica já presente na historiografia de língua alemã. Outro argumento é

${ }^{26}$ A diferenciação entre Höfler e Wenskus concerne em o primeiro ter noções tipicamente ideológicas e o segundo biologicistas.

${ }^{27} \mathrm{O}$ acesso e análise da Obra de Höfler é bastante problemática, assim utilizamos a perspectiva de Pohl na referente análise, fonte: POHL, W. Ethnicity, Theory, and Tradition: A Response. 
elencado por ser uma teoria externa a análise das fontes, não problematizando de forma complacente para elencar hipóteses na formação de interpretações sobre o contexto histórico do período. Goffart apresenta uma análise de fontes diferenciada, por entrar muito em estudos que referenciam obras narrativas, como Jordanes, Beda e Paulo diácono, problematizando sua veracidade. $\mathrm{O}$ caso de tais narrativas é o que elenca um passado mítico na formação de etnias, mas sua consideração é que pensar a Traditionskern seria algo desarticulado com o conteúdo da fonte em si, pois não proviriam tantas articulações para a formação de uma teoria. Para Goffart, os elementos de origem nas narrativas são isolados apenas como legitimador de uma origem, na formação de narrativas de tais populações. Sua análise não considera fontes orais como legítimas, pensando-as de forma, muitas vezes, “desconstrutiva”.

Alexander Callander Murray, continuador de uma concepção crítica desenvolvida inicialmente por Goffart, possui trabalhos mais pesados contrários à concepção da Universidade de Viena. Murray considera que o conceito polissêmico de etnogênese de Wenskus é baseado na ideia de origem da cultura germânica legitimada e sacralizada pelos ritos, mitos, nomes e genealogia ${ }^{28}$. O modo como Wenskus se apoiaria em uma antro-

28 "He (Wenskus) is not particularly sympathetic to Roman influence where questions of Germanic initiative, identity, and continuity are at stake. His book however is not principally about ethnic developments in the successor kingdoms but about processes which he argues were under way long before the encounter with Rome, never mind the creation of kingdoms in the western provinces. The image of the patient, elevating efforts of Roman genius (as espoused at n. 24 below) does not really fit his views. Wenskus still lays the foundation for most of what Pohl says in Strategies of Distinction (as at n. 1 ).” (MURRAY, 2002) 
pologia do século XIX fez Murray indicar alguns pontos como relevantes na continuidade do austríaco em uma historiografia anterior ${ }^{29}$. Para Murray, Pohl não acrescenta nada nas interpretações de Wenskus, por ser um pesquisador que continua com a defesa deste e apresentar um conceito de Tradionskern próximo.

Como crítica a esses historiadores de Toronto, Pohl aponta que o entendimento deles sobre a historiografia alemã está mais ligado a reflexões políticas atuais que sobre o período histórico das fontes. Na consideração contrária a uma teoria de forma crítica, sem pensar as mudanças nas noções conceituais, sempre legitimando o discurso contrário a uma teoria através de pensamentos políticos. ${ }^{30}$ Para Pohl, Murray ignora diversos casos apresentados nas fontes, o uso de simbologia romana, possibilidade de legitimação por mitos, interesses na origem desses povos, etc. No caso de Wenskus, seu trabalho indica uma quebra no paradigma da historiogra-

29 "Wenskus was no innovator as far as biological interpretations of early European history were concerned. A general historiographical perspective suggests different reasons for the popularity of his ideas. It is correct, I think, to point out that Wenskus's work came at the end of an historiographical development, not the beginning, encapsulating and systematizing half a century of scholarly revisionism in the areas of ethnology and Germanic antiquity. The work he produced is massive, drawing-often eclectically on philology, prehistory (archaeology), history, and social science; historians who know of it only by reputation may be surprised to learn that it begins with the palaeolithic.” (MURRAY, 2002)

30 "Murray happily ignores all this to put me back in line; his verdict has been clear from the start. In the language of myth, Otto Hofler went out to Germany where he met a monster, Heinrich Himmler, and then he begat Reinhard Wenskus, who begot Herwig Wolfram, who begot Walter Pohl. Apart from this one, I do not at all object to a reconstruction of scientific genealogies. No doubt the study of early medieval ethnicity is one of the fields that has always been most pervaded by ideology and partisan scholarship.” (POHL, 2002) 
fia de língua alemã, por apresentar objetivamente sua concepção longe de viés político apresentado anteriormente na historiografia. Pohl diferencia Höfler de Wenskus através de conceitos diferentes por cada autor, como na consolidação de poder em suas formas iniciais. Como Goffart e nem Murray apontam o uso de fontes orais, Pohl denota a fragilidade das críticas não apenas frente o desconhecimento dos autores, mas a não análise própria das fontes e implicâncias contextuais ${ }^{31}$.

\section{Outros Historiadores}

Entre outros historiadores que entram de alguma forma no conflito maior, podemos citar quatro. Em primeiro, Gillett, como um dos pesquisadores que possuem mais interesse nos embates historiográficos, aponta para o desenvolvimento de sua pesquisa por um viés alternativo. Para ele, utilizar o conceito de Traditionskern somente, ou fazer críticas desenfreadas, não são soluções para um melhor entendimento do período em pauta, mas pensar as fontes entendendo as sutilezas com documentos menores sobre narrativas basilares, muito utilizadas pela "Escola” de Toronto. Gillett é um pesquisador que aceita certas críticas apresentadas por Murray, principalmente ao que concerne a etnografia, mas admite alguns pontos de Viena, não desconsiderando que é possível fundamentar a concepção de

\footnotetext{
31 "Where more recent contributions have been taken into account, the main interest seems less to debate current views in their context, than to look for single statements that one could then expose as proof that the author is a die-hard, 1940s-style Germanophile. Typical of this method is how Murray picks, out of a fifty-four-page paper, a single sentence about the origin myth of the Lombards to conclude that my whole argument is based on the concepts of nineteenth-century germanische Altertumskunde." (POHL, 2002)
} 
Tradionskern e Identidade com fontes menores. Seu foco são as fontes e problemática, em suma. (C.f. GILLETT, 2002)

Outro historiador concerne a Kulikowski, o qual apresenta ideias diferentes a esse tipo de metodologia, evitando um tipo de "Ceticismo Epistemológico” ou até mesmo uma problematização historiográfica maior, mas que seria possível estudar os povos bárbaros de forma ativa pelas fontes escritas, interpretativamente. (C.f. KULIKOWSKI, 2002) Tal pesquisador considera que muitas discussões sobre tais conceitos tiram a importância que a própria análise das fontes teriam ${ }^{32}$, pois devido a poucos recursos, uma teoria maior não teria legitimidade como explicativa, nem fundamentação.

Bowlus possui uma discussão relevante acerca dos embates historiográficos, sua perspectiva está na crítica de como tais conceitos são utilizáveis apenas no contexto Godo, objeto mais importante devido às publicações em língua inglesa por Wolfram, Heather e Amory. Bowlus pesquisou outras tribos germânicas, como os Bávaros e considerou que tais perspectivas não entrariam como autênticas na análise de tais microcosmos. Historiograficamente, o autor discute a parte teórica da etnogênese, o que o aproxima em diversos pontos da perspectiva de Toronto. (C.f. BOWLUS, 2002).

\section{Conclusões Parciais}

Através da referida análise apresentada nesse trabalho, podemos perceber que as maiorias das discussões em pauta concernem ao entendi-

\footnotetext{
32 "though our sources distort barbarian reality, we can get behind their words to discover what barbarian collectivities were really like.” (KULIKOWSKI. 2002).
} 
mento de determinados conceitos por parte da historiografia. Wenkus, além de ser considerado um pesquisador na área, apresenta-se como própria fonte, devido aos seus estudos e caráter ímpar na formação paradigmática do conhecimento da área da Antiguidade Tardia. Frente às discussões historiográficas, os embates estão localizam-se dentro e fora dos conceitos, em ideias que remetem tanto uma base teórica quando conjuntural do período histórico em debate, em que podemos providenciar um melhor entendimento da área em análise. Os embates entre as "Escolas” de Viena e Toronto, além de historiadores sem vínculos são sólidos a linhas interpretativas, demonstram como a referida área possui discussões pesadas e intensas, denotando movimento dentro do campo historiográfico. Interessante como as discussões, no desenvolvimento de respostas a trabalhos específicos e concepções, remontam a poucas ocasiões na história, tornando o conhecimento mais produtivo.

\section{Bibliografia:}

FRIGHETTO, R. Antiguidade Tardia: Roma e as Monarquias Romano - Bárbaras numa época de Transformações (Séculos II-VIII). Curitiba: Juruá, 2012.

GILLETT, A. (Ed). On Barbarian Identity; Critical Approaches to Ethnicity in the Early Middle Ages. Turnhout: Brepols, 2002.

GILLETT, A. Ethnogenesis: A Contested Model of Early Medieval Europe. In: History Compass 4. Oxford, Blackwell. p. 1-20. 2006.

GOETZ, H.W., JARNUT, J.; POHL, W. (Eds.). Regna and Gentes: the relationship between late antique and early medieval peoples and kingdoms in the transformation of Roman World. Leiden-Boston: Brill, 2003. 
Cadernos de Clio, Curitiba, n. ${ }^{\circ}$ 4, 2013

GOFFART. W. The Narrators of Barbarian History -A.D. 550-800 Jordanes-Gregory of Tours-Bede And Paul the Deacon. New Jersey: Princeton University Press, 1988.

MOMIGLIANO. A. Alien Wisdom: The Limits of Hellenization. Cambridge: Cambridge University Press, 1990.

MURRAY. A. C. (Ed.) After Rome's Fall: Narrators and Sources of Early Medieval History. Toronto: University of Toronto Press, 1998.

POHL, W; REIMITZ, H. Strategies of Distinction. The construction of Ethnic Communities, 300-800. Leiden-Boston-Köln: Brill, 1997.

WOLFRAM, H. History of the Goths. Berkeley and Los Angeles, California: University of California Press, 1990. 